\title{
Ruthenium Sensitizer with Thienothiophene-Linked Carbazole Antennas in Conjunction with Liquid Electrolytes for Dye-Sensitized Solar Cells
}

\author{
Chia-Yuan Chen, ${ }^{\dagger}$ Nuttapol Pootrakulchote, ${ }^{\dagger}$ Tzu-Hao Hung, ${ }^{+}$Chun-Jui Tan, ${ }^{+}$Hui-Hsu Tsai, $^{+}$ \\ Shaik M. Zakeeruddin, ${ }^{*, \neq}$ Chun-Guey $\mathrm{Wu}^{*,+}$ and Michael Grätzel ${ }^{*, \neq}$ \\ ${ }^{\dagger}$ Department of Chemistry, National Central University, Jhong-Li, 32001, Taiwan, ROC. \\ ${ }^{\ddagger}$ Laboratory for Photonics and Interfaces, Swiss Federal Institute of Technology, CH 1015, Lausanne, Switzerland.
}

\begin{abstract}
A new heteroleptic ruthenium complex, coded CYC-B12, incorporating an antenna ligand composed of sequential connections of a thienothiophene conjugated bridge and carbazole hole-transport moiety was prepared. This new sensitizer exhibits a lower energy MLCT band centered at $555 \mathrm{~nm}$ with a high molar absorption coefficient of $2.24 \times 10^{4} \mathrm{M}^{-1} \mathrm{~cm}^{-1}$. The device sensitized by CYC-B12 in conjunction with a volatile electrolyte shows a high photovoltaic efficiency of $9.4 \%$ under an illumination of standard global AM 1.5G sunlight. With a low-volatile electrolyte, the cell based on this new sensitizer shows not only a good conversion efficiency of $8.2 \%$ but also excellent durability (>96\%) under light soaking at $60^{\circ} \mathrm{C}$ in a simulated sunlight for $1000 \mathrm{~h}$. The difference in the electron recombination kinetics caused by various liquid electrolytes or aging process is also investigated by employing the transient photoelectrical measurements.
\end{abstract}

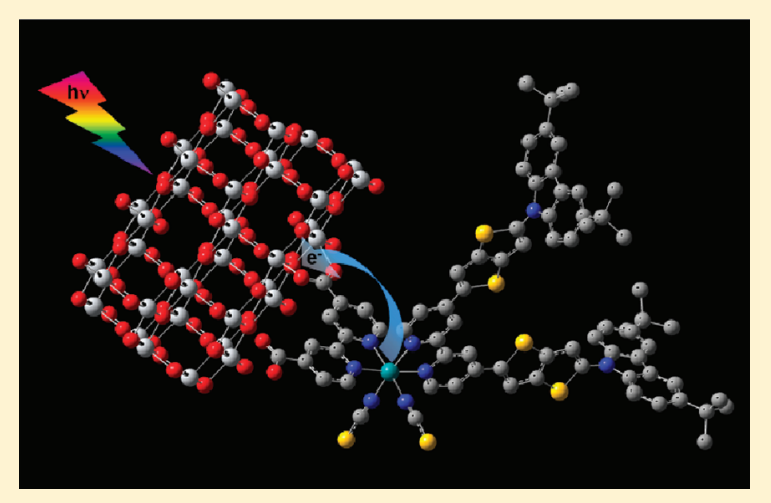

\section{INTRODUCTION}

Dye-sensitized solar cells (DSSCs) have been developed as one of the promising photovoltaic technologies in virtue of their low manufacture cost, tunable absorption range, impressive photon-to-current conversion efficiency , as well as semitransparency and flexibility. ${ }^{1}$ In DSSC, the dye molecule (sensitizer) selfassembled onto the surface of wide-band gap semiconductor, $\mathrm{TiO}_{2}$, plays a vital role in the light-harvesting, charge separation, and overall photon-to-current conversion efficiency of the devices. Under illumination, ultraswift electron injection from photoexcited sensitizers into the conduction band of the semiconductor occurs and the hole in the dye is regenerated sequentially by electron donation from the redox electrolyte. Numerous efforts focused on optimizing the molecular structures of the sensitizers and modulating the composition of electrolytes have been made to enhance the photovoltaic performance and improve the durability of the devices. ${ }^{2-6}$ Among numerous dyes designed for DSSCs, the ruthenium-based sensitizers incorporating thiophene derivatives have been proven to be excellent candidates to realize highly efficient and robust devices. $^{7-21}$ In addition, another new branch of heteroleptic ruthenium sensitizers endowed with the ancillary ligand consisting of a conjugated bridge and a hole-transporting terminal have been developed toward enriching the light-capturing ability to match the solar radiation and retarding the charge recombination between the dye-sensitized n-type semiconductor and electrolyte. ${ }^{22-26}$ Here we report a new ruthenium sensitizer, coded CYC-B12
(Figure 1), featuring carbazoles as the molecular terminals of the ancillary ligand. Apart from characterizing its intrinsic optoelectronic properties, we test CYC-B12 in combination with various liquid electrolytes and examine the interfacial electron recombination dynamics between the injected electrons at $\mathrm{TiO}_{2}$ and triiodide ions with transient photoelectrical measurements.

\section{EXPERIMENTAL SECTION}

2.1. Materials and Characterization. All reagents were obtained from the commercial sources and used as received unless specified. Solvents were dried over sodium or $\mathrm{CaH}_{2}$ before use. The structures of CYC-B12 dye and its intermediates were identified with ${ }^{1} \mathrm{H}$ NMR spectra. The structure of CYC-B12 dye was further confirmed by FAB-MS and elemental analysis. ${ }^{1} \mathrm{H}$ NMR spectra were recorded with a Bruker $300 \mathrm{MHz}$ or DRX$500 \mathrm{NMR}$ spectrometer in $\mathrm{CDCl}_{3}$ or $\mathrm{DMSO}-\mathrm{d}_{6}$. FAB-MS spectra were obtained using JMS-700 HRMS. Elemental analyses were carried out with a Heraeus $\mathrm{CHN}-\mathrm{O}-\mathrm{S}$ Rapid-F002 analysis system. UV/vis spectra were measured using a Cary 300 Bio spectrometer. Electrochemical study of the metal complexes in solution was performed in a single-compartment, three-electrode

Received: July 5, 2011

Revised: $\quad$ August 26, 2011

Published: August 31, 2011 


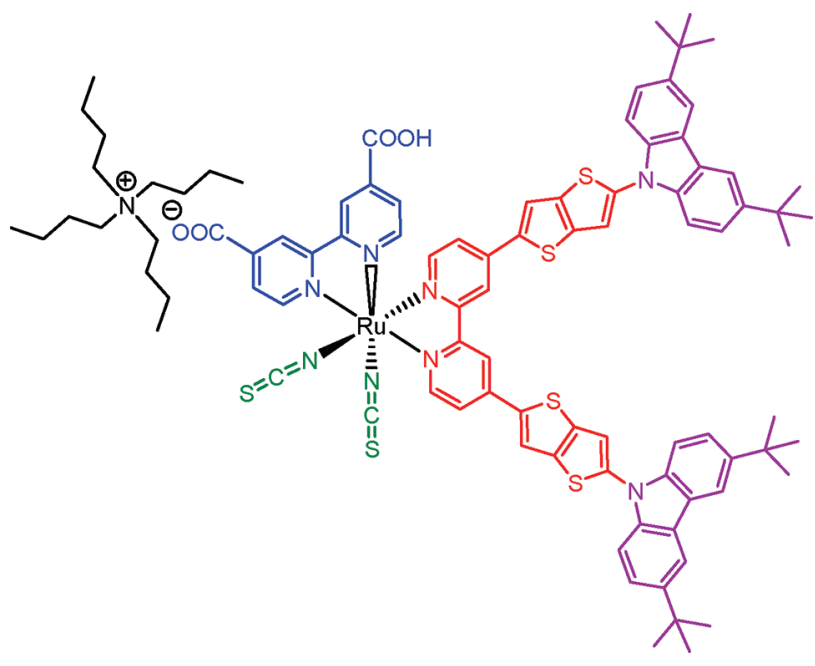

Figure 1. Molecular structure of CYC-B12.

cell with a platinum disk working electrode and a Pt wire counter electrode. The reference electrode was $\mathrm{Ag} / \mathrm{Ag}^{+}$and the supporting electrolyte was $0.1 \mathrm{M}$ tetrabutylammonium hexafluorophosphate $\left(\mathrm{TBAPF}_{6}\right)$ in DMF. The square-wave voltammograms (potential step increment: $10 \mathrm{mV}$; frequency: $25 \mathrm{~Hz}$ ) were recorded using a potentiostat/galvanostat (PGSTAT 30, Autolab, Eco-Chemie, The Netherlands) and ferrocene was used as a calibration standard.

2.2. Synthesis of 3,6-Bis-t-butyl-9-(2-thieno[3,2-b]thienyl) carbazole (3). The starting materials, 2-bromo-thieno[3,2-b]thiophene (1), and 3,6-bis-t-butyl carbazole (2) were prepared according to the procedures reported in literature. ${ }^{27,28} \mathrm{~A}$ total of $3.36 \mathrm{~g}(12.0 \mathrm{mmol})$ of 3,6-bis-t-butyl carbazole, $1.85 \mathrm{~g}(10.0 \mathrm{mmol})$ of $\mathrm{Cu}$-bronze, and $1.80 \mathrm{~g}(13.1 \mathrm{mmol})$ of $\mathrm{K}_{2} \mathrm{CO}_{3}$ were added into the solution that consisted of $2.20 \mathrm{~g}(10.0 \mathrm{mmol})$ of 2-bromothieno[3,2-b] thiophene dissolved in $100 \mathrm{~mL}$ of nitrobenzene. After the mixture was refluxed under argon for $36 \mathrm{~h}$, the nitrobenzene was removed by distillation under vacuum. The reaction was terminated by suspending the residue in the mixture of $300 \mathrm{~mL}$ of $\mathrm{CHCl}_{3}, 100 \mathrm{~mL}$ of $\mathrm{H}_{2} \mathrm{O}$, and $150 \mathrm{~mL}$ of saturated $\mathrm{NH}_{4} \mathrm{OH}$ aqueous solution. The organic layer was extracted with $\mathrm{CHCl}_{3}$ after the mixture was stirred continuously for $2 \mathrm{~h}$. Then the collected organic layer was washed further with excess water and saturated $\mathrm{NaCl}$ aqueous solution, respectively, and then dried over $\mathrm{Na}_{2} \mathrm{SO}_{4}$. After rotary evaporation of the solvent, the crude product was purified by chromatography on silica gel eluted with hexane/ethyl acetate (10:1) to afford $2.59 \mathrm{~g}(61.7 \%$ yield $)$ of the pure product. ${ }^{1} \mathrm{H}$ NMR $(300 \mathrm{MHz}$, $\delta / \mathrm{ppm}$ in $\left.\mathrm{CDCl}_{3}\right): 8.10(\mathrm{dd}, 2 \mathrm{H}), 7.50(\mathrm{~d}, 1 \mathrm{H}), 7.47(\mathrm{~d}, 1 \mathrm{H})$, 7.46 (s, 1H), 7.43 (d, 2H), 7.39 (d, 1H), 7.32 (d, 1H), 1.45 (s, 18H).

2.3. Synthesis of 3,6-Bis-t-butyl-9-(8-trimethylstannyl-2thieno[3,2-b]thienyl) carbazole (4). A total of $2.93 \mathrm{~mL}$ of $n$ $\mathrm{BuLi}$ (2.5 $\mathrm{M}$ in hexane) was added into the solution of 3,6-bis-tbutyl-9-(2-thieno[3,2-b] thienyl) carbazole $(2.55 \mathrm{~g}, 6.12 \mathrm{mmol})$ dissolved in $80 \mathrm{~mL}$ of anhydrous THF at $-78{ }^{\circ} \mathrm{C}$. The mixture was stirred for $2 \mathrm{~h}$, and then $1.58 \mathrm{~g}$ of trimethyltin chloride in anhydrous THF was added. The mixture was stirred overnight at room temperature. The reaction was terminated by adding saturated $\mathrm{NaCl}$ aqueous solution and the product was extracted with $\mathrm{CH}_{2} \mathrm{Cl}_{2}$. Collected the organic layer, removed the solvent to afford $3.47 \mathrm{~g}$ (98\% yield) of crude product of 3,6-bis-t-butyl-9-(8trimethylstannyl-2-thieno[3,2-b] thienyl) carbazole. This crude product was used without further purification.

2.4. Synthesis of Ligand-12 (5). This ancillary ligand was prepared by Stille coupling of 3,6-bis-t-butyl-9-(8-trimethylstannyl2-thieno[3,2-b] thienyl) carbazole and 4,4'-dibromo-2,2' -bipyridine. 3.47 g of 3,6-bis-t-butyl-9-(8-trimethylstannyl- 2-thieno$[3,2-b]$ thienyl) carbazole; $0.87 \mathrm{~g}$ of $4,4^{\prime}$-dibromo-2,2'-bipyridine were dissolved in $85 \mathrm{~mL}$ of anhydrous DMF, and then $0.38 \mathrm{~g}$ of $\mathrm{Pd}\left(\mathrm{PPh}_{3}\right)_{4}$ was added as a catalyst. The mixture was refluxed under argon for $48 \mathrm{~h}$. After cooling to room temperature, $5 \mathrm{wt} \%$ $\mathrm{NH}_{4} \mathrm{Cl}_{(\text {aq })}$ was added to terminate the reaction and the product was extracted with $\mathrm{CHCl}_{3}$. The organic layer was washed with saturated $\mathrm{NaHCO}_{3(\mathrm{aq})}$, distilled water and saturated $\mathrm{NaCl}_{(\text {aq) }}$, respectively. The crude product was purified with Soxhlet using hexane as a solvent to remove nonreacted reagent 3,6-bis-t-butyl9-(8- trimethylstannyl-2-thieno[3,2-b]thienyl) carbazole and then using $\mathrm{CHCl}_{3}$ to extract the product Ligand-12 (82.7\% yield). ${ }^{1} \mathrm{H}$ $\operatorname{NMR}\left(300 \mathrm{MHz}, \delta / \mathrm{ppm}\right.$ in $\left.\mathrm{CDCl}_{3}\right): \delta 8.77(\mathrm{~d}, 4 \mathrm{H}), 8.12(\mathrm{~s}, 4 \mathrm{H})$, 7.93 (s, 2H), 7.60 (d, 2H), 7.51 (d, 8H), 7.43 (s, 2H), 1.47 (s, 36H). MS: $m / z 986.35\left([\mathrm{M}]^{+}\right)$; LRFAB-MS found: $m / z 987.6(\mathrm{~m})$ $\left([\mathrm{M}+\mathrm{H}]^{+}\right)$. HRFAB-MS found: $986.3540\left([\mathrm{M}]^{+}\right)$.

2.5. Synthesis of CYC-B12 (TBA(Ru[(4-carboxylic acid-4'carboxylate- 2,2'-bipyridine) (Ligand-12) (NCS) ${ }_{2}$ ]) (6). CYCB12 was synthesized using the one-pot synthetic procedure ${ }^{7}$ as reported previously and then purified further on Sephadex LH20 using methanol as an eluent: $0.31 \mathrm{~g}(0.51 \mathrm{mmol})$ of $\left[\mathrm{RuCl}_{2}(\mathrm{p}\right.$ cymene $)]_{2}, 1.00 \mathrm{~g}(1.01 \mathrm{mmol})$ of Ligand-12 (5), $0.25 \mathrm{~g}$ (1.01 mmol) of dcbpy $\left(4,4^{\prime}\right.$-dicarboxylic acid-2,2'-bipyridine $)$, and excess $\mathrm{NH}_{4} \mathrm{NCS}$ were used in the reaction. The crude product was dissolved in the mixture of methanol and tetra-butyl ammonium hydroxide (TBAOH) aqueous solution (40 wt \% in $\mathrm{H}_{2} \mathrm{O}$ ) and then purified on a Sephadex LH-20 column using methanol as an eluent. The main band was collected and the $\mathrm{pH}$ value of the collected solution was lowered to ca. 5.8 by adding dilute $\mathrm{HNO}_{3}$. The collected precipitate was washed with water and dried under vacuum. After purification, $0.62 \mathrm{~g}(0.37 \mathrm{mmol}, 36.3 \%$ yield $)$ of CYCB12 was obtained. MS: $m / z$ 1689.5 $\left([\mathrm{M}]^{+}\right)$LRFAB-MS found: $m / z$ $1449.6(\mathrm{~m})\left(\left[\mathrm{M}+\mathrm{H}-\mathrm{N}\left(\mathrm{C}_{4} \mathrm{H}_{9}\right)_{4}\right]^{+}\right) ; 1391.6(\mathrm{~s})([\mathrm{M}+\mathrm{H}-\mathrm{N}-$ $\left.\left.\left(\mathrm{C}_{4} \mathrm{H}_{9}\right)_{4}-\mathrm{NCS}\right]^{+}\right)$. HRFAB-MS found: $1448.2581([\mathrm{M}+\mathrm{H}-\mathrm{N}-$ $\left.\left(\mathrm{C}_{4} \mathrm{H}_{9}\right)_{4}\right]^{+}$). Elemental analysis: calcd. for $\mathrm{C}_{92} \mathrm{H}_{101} \mathrm{~N}_{9} \mathrm{O}_{4} \mathrm{RuS}{ }_{6} \cdot$ $3 \mathrm{H}_{2} \mathrm{O}$ : C, 63.35; H, 6.18; N, 7.23; S, 11.03\%. Found: C, 63.43; H, 5.78; N, 7.38; S, $11.43 \% .{ }^{1} \mathrm{H}$ NMR (500 MHz, $\delta /$ ppm in DMSO-d $d_{6}$, $J \mathrm{~Hz}): 9.36(\mathrm{~d}, J=5.4 \mathrm{~Hz}, 1 \mathrm{H}) ; 9.30(\mathrm{~d}, J=5.8 \mathrm{~Hz}, 1 \mathrm{H}) ; 9.23(\mathrm{~s}, 1 \mathrm{H})$; $9.11(\mathrm{~s}, 1 \mathrm{H}) ; 9.08(\mathrm{~s}, 1 \mathrm{H}) ; 8.96(\mathrm{~s}, 1 \mathrm{H}) ; 8.71(\mathrm{~s}, 1 \mathrm{H}) ; 8.51(\mathrm{~s}, 1 \mathrm{H})$; $8.33(\mathrm{~s}, 2 \mathrm{H}) ; 8.27(\mathrm{~m}, 4 \mathrm{H}) ; 8.00(\mathrm{~s}, 1 \mathrm{H}) ; 7.91(\mathrm{~d}, J=5.8 \mathrm{~Hz}, 1 \mathrm{H})$; $7.89(\mathrm{~s}, 1 \mathrm{H}) ; 7.63(\mathrm{~d}, J=5.8 \mathrm{~Hz}, 1 \mathrm{H}) ; 7.57(\mathrm{~m}, 4 \mathrm{H}) ; 7.50(\mathrm{~m}, 6 \mathrm{H})$; $3.16(\mathrm{~m}, 8 \mathrm{H}) ; 1.56(\mathrm{~m}, 8 \mathrm{H}) ; 1.43(\mathrm{~s}, 18 \mathrm{H}) ; 1.40(\mathrm{~s}, 18 \mathrm{H}) ; 1.30(\mathrm{~m}$, $8 \mathrm{H}) ; 0.93(\mathrm{t}, J=7.3 \mathrm{~Hz}, 12 \mathrm{H})$.

2.6. Device Fabrication. A mesoscopic $\mathrm{TiO}_{2}$ film composed of a $7 \mu \mathrm{m}$ thick transparent layer of $20 \mathrm{~nm}$ sized $\mathrm{TiO}_{2}$ anatase nanoparticles onto which a second $5 \mu \mathrm{m}$ thick scattering layer of $400 \mathrm{~nm}$ sized $\mathrm{TiO}_{2}$ was superimposed. The detailed methods for $\mathrm{TiO}_{2}$ film preparation, device fabrication, and the characteristic photocurrent-voltage measurements can be found in the earlier report. ${ }^{29}$ The double layer films were heated to $520^{\circ} \mathrm{C}$, sintered for $30 \mathrm{~min}$, cooled to $80{ }^{\circ} \mathrm{C}$, and then immersed into the dye solution $(300 \mu \mathrm{M})$ containing a $10 \% \mathrm{DMSO}$ in acetonitrile and tert-butyl alcohol (volume ratio: 1:1) mixture, respectively, with $75 \mu \mathrm{M}$ DINHOP ${ }^{30}$ as a coadsorbent for $16 \mathrm{~h}$. In device $\mathrm{D}$, the electrolyte code Z960 (1.0 M 1,3-dimethylimidazolium iodide (DMII), $50 \mathrm{mM}$ LiI, $30 \mathrm{mM} \mathrm{I}_{2}, 0.5 \mathrm{M}$ tert-butylpyridine, and 
Scheme 1. Preparation of Ancillary Ligand-12 (5)

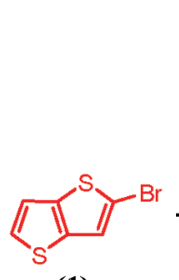

(1)

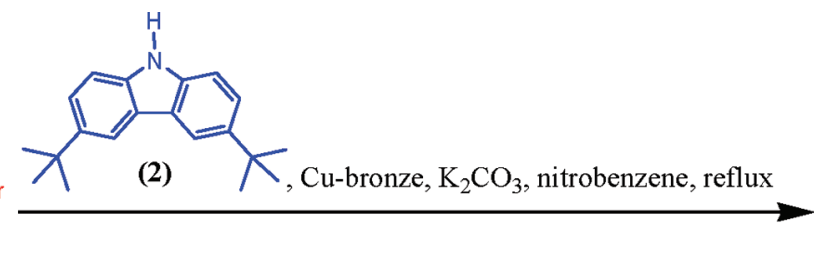

.

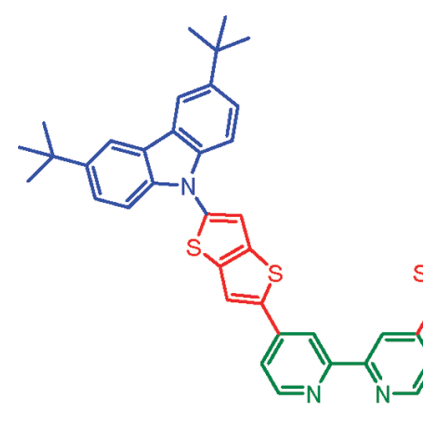

$Y$

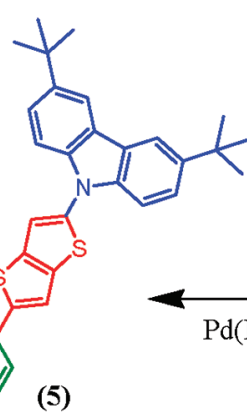

(5)

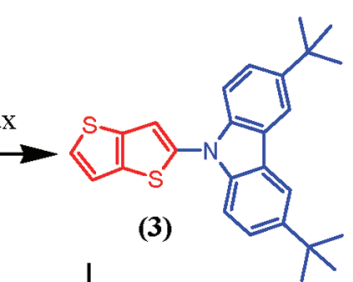

(3)

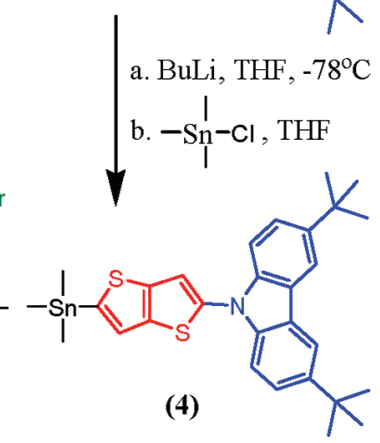

0.1 M guanidinium thiocyanate (GNCS) in the mixed solvent of acetonitrile and valeronitrile $(\mathrm{v} / \mathrm{v}, 85 / 15))$ was used.

2.7. Dye Loading Experiment. Two transparent $\mathrm{TiO}_{2}$ films with $8 \mu \mathrm{m}$ thickness were immersed in each of the dye solution; $0.3 \mathrm{mM}$ CYC-B12 and Z907Na, prepared in acetonitrile and tertbutyl alcohol (volume ratio: $1: 1$ ) with $10 \%$ DMSO as a solvent. After dipping into these dye solutions for $15 \mathrm{~h}$, the sensitized films were rinsed with acetronitrile for several minutes. Then the dye was desorbed from the $\mathrm{TiO}_{2}$ surface by immersing the films in a solution of tetra-butyl ammonium hydroxide (TBAOH) in dimethylformamide (DMF) with concentration of $0.1 \mathrm{~g} / \mathrm{mL}$. The number of dye molecules absorbed on the $\mathrm{TiO}_{2}$ surface was determined by acquiring an absorption spectrum of the dye solution using a UV/vis spectrometer.

2.8. Transient Photoelectrical Measurements. In the transient photoelectrical decay experiments, different steady-state light levels were provided by a homemade white light-emitting diode array tuning the driving voltage. A red light-emitting diode array controlled with a fast solid-state switch was used to generate a perturbation pulse of $50 \mathrm{~ms}$ duration. The pulsed red- and steady-state white-light were both shed on the working electrode side of the test cell. The intensity of the red light pulse was carefully controlled by the driving potential of the red diode array to keep the modulated photovoltage below $10 \mathrm{mV}$. In transient photovoltage decay measurement, the cell was maintained at open circuit voltage under the white light and the transient photovoltage decay following the red light pulse was monitored. Normally, the decay follows closely a monoexponential form, thus the recombination rate constant can be extracted from the slope of the semilogarithmic plot.

2.9. Device Stability Test. The cell was covered with a $50 \mu \mathrm{m}$ thick polyester film acting as a UV cutoff filter for the accelerated testing. The test was performed under the visible light illumination ( $1 \mathrm{sun} ; 100 \mathrm{~mW} / \mathrm{cm}^{2}$ ) at $60^{\circ} \mathrm{C}$, and the photovoltaic performance during the test was recorded. The physicochemical measurements were conducted at room temperature after the cell was equilibrated and cooled down to room temperature.

\section{RESULTS AND DISCUSSION}

The ancillary ligand in CYC-B12 was constructed for the first time by using the Ullmann $\mathrm{N}$-arylation to link the conjugate 2-bromo-thieno[3,2-b] thiophene and 3,6-bis-t-butyl carbazole units. Stille coupling was employed to subsequently connect the antennas to the bipyridine ligand. The synthetic procedure for the ancillary ligand is shown in Scheme 1. The CYC-B12 complex was synthesized using the typical one-pot synthetic procedure. ${ }^{7}$ The detailed synthetic procedure and the identification of the molecular structure are described in the Experimental Section. Since CYC-B12 was isolated in the monoprotonated form containing one tetra-butyl ammonium (TBA) cation, two possible configurations of CYC-B12 (CYC-B12 (a): the TBA cation is located nearby the carboxyl pyridine trans to NCS group; CYC-B12 (b): the TBA cation is placed around another carboxyl pyridine trans to the antennas) may coexist in the product. Therefore, the molecular orbitals of CYC-B12 in DMF for both configurations were investigated by using the density functional theory (DFT) calculation with Gaussian 09 program $^{31}$ adopting the Becke, three-parameter, Lee-Yang-Parr (B3LYP) function. The DGauss Double-Zeta Valence Polarized (DGDZVP) basis set ${ }^{32,33}$ in combination with the Conductor-like Polarizable Continuum Model (C-PCM $)^{34,35}$ were also used to account for the solvation effect to optimize the geometry of CYC-B12 in DMF. For calculation convenience, the butyl groups in CYC-B12 were replaced by methyl groups. The graphical representation of the calculated frontier orbitals is shown in Figure 2. The LUMO (lowest unoccupied molecular orbital) is mainly localized on the tetra-butyl ammonium 4-carboxylic acid-4'-carboxylate anchoring ligand, LUMO+1 is contributed from the mixed orbitals of anchoring and antenna-ancillary ligand and LUMO+2 is dominated by the ancillary ligand. On the other hand, the HOMO (highest occupied molecular orbital), HOMO-1 and HOMO-2 are all contributed primarily from the Ru-NCS mixed orbitals. Comparing the two configurations, CYC-B12 (a) and CYC-B12 (b), the DFT calculation suggests that the TBA cation has a significant influence on the localization of LUMO and LUMO+1 but no 


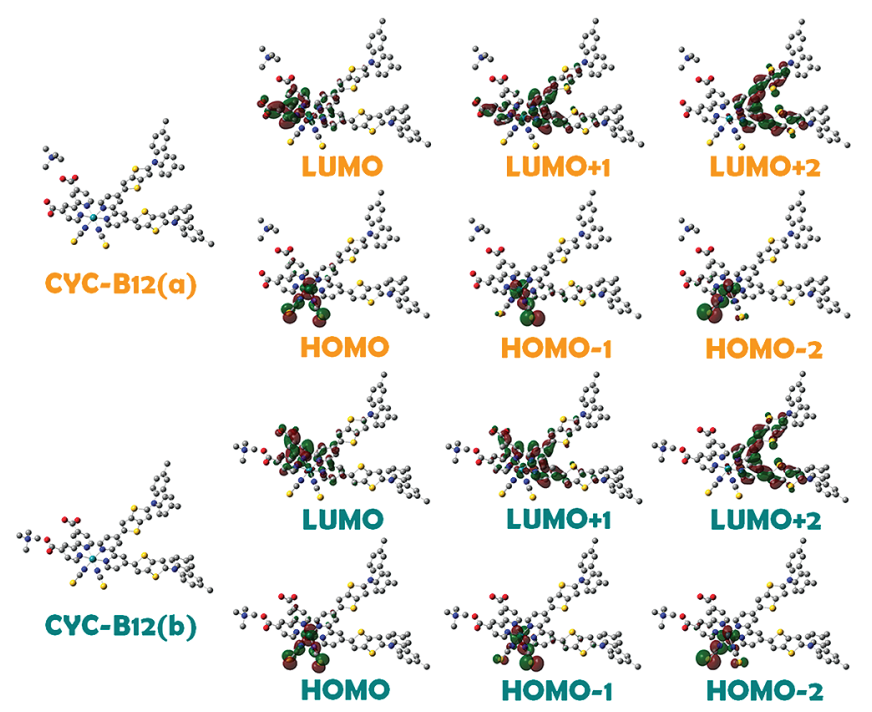

Figure 2. Isodensity surface plots of the frontier orbitals (LUMO+2, LUMO+1, LUMO, HOMO, HOMO-1 and HOMO-2) of CYC-B12 (a) and CYC-B12 (b); isodensity value $=0.03$.

apparent impact on the HOMOs and LUMO+2. However more detailed theoretical studies, combined with experimental data are needed to assign the docking site of TBA in a heteroleptic ruthenium complex.

The electronic absorption spectrum of CYC-B12 measured in DMF is displayed in Figure 3. CYC-B12 exhibits intense absorption bands centered at 393 and $555 \mathrm{~nm}$, respectively. The band at $393 \mathrm{~nm}$ is assigned to the overlap of $\pi-\pi^{*}$ transitions of the ancillary ligand and one of the MLCT bands for CYC-B12. Another peak with $\lambda_{\max }$ at $555 \mathrm{~nm}$ and molar absorption coefficient $(\varepsilon)$ of $2.24 \times 10^{4} \mathrm{M}^{-1} \mathrm{~cm}^{-1}$ is attributed to the characteristic MLCT transition which is effective in charge generation by visible light in the devices sensitized by CYC-B12. Comparing the absorption profile of CYC-B12 with that of ${\mathrm{CYC}-\mathrm{B} 13^{25}}$ bearing ethylenedioxy-thiophene (EDOT) as $\pi$-bridge in the ancillary ligand, we find that the lower-energy MLCT band of CYC-B12 slightly red-shifted and the corresponding $\varepsilon$ value increased. These results indicate that the thieno[3,2-b] thiophene is a superior spacer in reinforcing the light-harvesting ability of ruthenium dyes. To gain more insights into these absorption bands of CYC-B12 and to investigate the position of TBA cation, the time-dependent density functional theory (TD-DFT) calculation of the singlet-singlet electronic transition for CYC-B12 (a) and CYC-B12 (b) were performed based on the corresponding optimized geometry calculated at the B3LYP/DGDZVP level, and the calculated absorption spectra are also presented in Figure 3. The experimental and TD-DFT calculated absorption spectra of CYC-B12 in DMF show a good match based on the excitation energy. The calculated absorption profile of CYC-B12 (a) and CYC-B12 (b) are both close to the experimental result. Given the broad features of CYC-B12 absoption band it is difficult to attribute a specific TBA docking site. Therefore TBA cation may be either on the pyridine trans to NCS group (CYC-B12 (a)) or pyridine trans to pyridine (CYCB12 (b)) when CYC-B12 is dissolved in DMF. The location of cation in monoprotonated heteroleptic ruthenium sensitizers may be different at various solvent environment. For clarifying the docking site of TBA in CYC-B12, the TD-DFT calculations with different solvents and $\mathrm{TiO}_{2}$ cluster is now in progress.

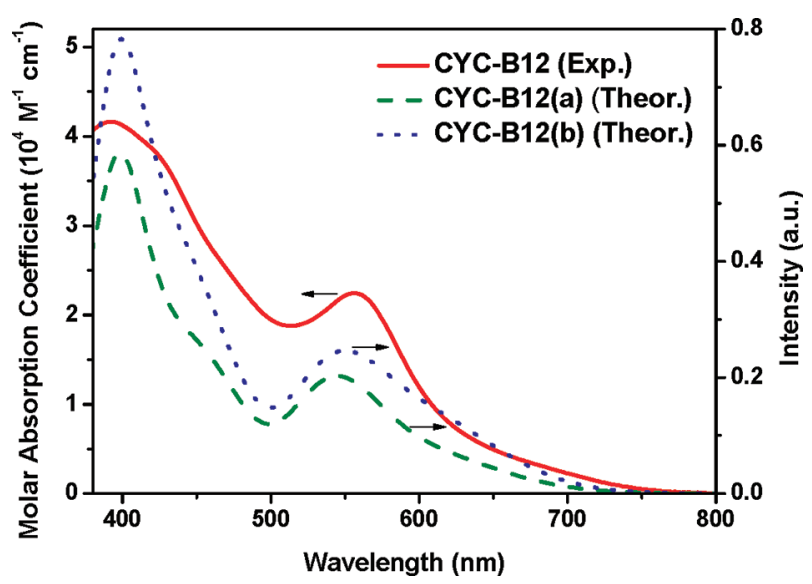

Figure 3. Comparison between experimental and theoretical absorption spectra of CYC-B12 in DMF. The calculated spectra of CYC-B12 (a) and CYC-B12 (b) were obtained by Gaussian convolution with $\sigma=$ $0.15 \mathrm{eV}$.

On the other hand, to know how the excited state transitions related to the electron transfer in CYC-B12 dissolved in DMF, the major orbital contributions of the transitions with energy lower than $2.48 \mathrm{eV}$ were analyzed since they play an important role in converting low-energy photons into electricity when used in DSSCs. The excitation energies, oscillator strengths and their corresponding transition assignments of both CYC-B12 (a) and CYC-B12 (b) are listed in Table 1. The TD-DFT calculation data reveal that the experimental absorption band centered at $555 \mathrm{~nm}$ is mainly contributed from the 547.2 and $541.1 \mathrm{~nm}$ excitations with the high oscillator strength of 0.1582 and 0.1301 , respectively for CYC-B12 (a). The calculated vertical transition data for CYC-B12 (b) are close to those for CYC-B12 (a). The MLCT band is majorly from 551.7 and $550.5 \mathrm{~nm}$ excitations with the oscillator strength of 0.1554 and 0.0548 , respectively. In these transitions, the Ru-NCS mixed orbitals (such as HOMO-1 and HOMO-2) and the $\pi^{*}$ orbitals of anchoring ligand (LUMO and $\mathrm{LUMO}+1$ ) are predominantly involved (the electron localization on these orbitals are shown in Figure 2). Both transition bands are regarded as metal-to-ligand charge transfer transitions which are known as the most important/high efficient first step to convert photon into electricity in DSSC. The high molar absorption coefficient for the band center at $555 \mathrm{~nm}$ (which is an effective MLCT transition) suggests that CYC-B12 is a good sensitizer to be applied in DSSCs.

The energy levels of the ground and excited states for CYCB12 were estimated by square-wave voltammetry in combination with the optical transition energy, $E_{0-0}$, determined from the absorption onset. These values are important to understand whether there is enough driving force to inject electrons into the $\mathrm{TiO}_{2}$ conduction band and to regenerate the neutral dye by electron donation from the redox electrolyte present in the cell. The oxidation potential of CYC-B12 is $0.98 \mathrm{~V}$ versus NHE $(-5.48 \mathrm{eV}$ versus vacuum), which is ca. $0.58 \mathrm{~V}$ more positive than the redox potential of the iodide/triiodide couple used in the liquid electrolyte. The optical transition energy, $E_{0-0}$, for CYC-B12 is $1.58 \mathrm{eV}$ and by neglecting the entropy changes during excitation, the excited-state redox potential, $\phi^{0}\left(\mathrm{~S}^{+} / \mathrm{S}^{*}\right)$ is $-0.60 \mathrm{~V}$ versus NHE $(-3.90 \mathrm{eV}$ versus vacuum), which is more negative than the potential (ca. $-0.50 \mathrm{~V}$ versus $\mathrm{NHE}$ ) of the $\mathrm{TiO}_{2}$ (anatase) conduction band edge. These results clearly show 
Table 1. Properties of Ground-State Vertical Excitation with the Energy Lower $2.48 \mathrm{eV}$ and Oscillator Strengths $(f)$ Larger than 0.01

\begin{tabular}{|c|c|c|}
\hline transition energy/nm & oscillator strength $(f)$ & transition assignment $(\mathrm{H}=\mathrm{HOMO} ; \mathrm{L}=\mathrm{LUMO})$ \\
\hline \multicolumn{3}{|r|}{ CYC-B12 (a) } \\
\hline 644.7 & 0.0167 & $\mathrm{H} \rightarrow \mathrm{L}(85 \%), \mathrm{H} \rightarrow \mathrm{L}+1(11 \%)$ \\
\hline 613.4 & 0.0700 & $\mathrm{H} \rightarrow \mathrm{L}+1(78 \%), \mathrm{H} \rightarrow \mathrm{L}(12 \%), \mathrm{H}-1 \rightarrow \mathrm{L}+1(4 \%)$. \\
\hline 547.2 & 0.1582 & $\mathrm{H}-1 \rightarrow \mathrm{L}+1(48 \%), \mathrm{H}-2 \rightarrow \mathrm{L}+1(31 \%), \mathrm{H}-1 \rightarrow \mathrm{L}(15 \%)$. \\
\hline 541.1 & 0.1301 & $\mathrm{H}-2 \rightarrow \mathrm{L}(70 \%), \mathrm{H}-2 \rightarrow \mathrm{L}+1(21 \%), \mathrm{H}-1 \rightarrow \mathrm{L}+1(5 \%)$ \\
\hline 518.5 & 0.0189 & $\mathrm{H}-2 \rightarrow \mathrm{L}+1(39 \%), \mathrm{H}-2 \rightarrow \mathrm{L}(20 \%), \mathrm{H}-1 \rightarrow \mathrm{L}+1(14 \%), \mathrm{H}-1 \rightarrow \mathrm{L}(9 \%), \mathrm{H} \rightarrow \mathrm{L}+1(6 \%), \mathrm{H} \rightarrow \mathrm{L}+2(5 \%), \mathrm{H} \rightarrow \mathrm{L}+3(2 \%)$ \\
\hline \multicolumn{3}{|r|}{ CYC-B12(b) } \\
\hline 626.4 & 0.0719 & $\mathrm{H} \rightarrow \mathrm{L}(88 \%), \mathrm{H}-2 \rightarrow \mathrm{L}(5 \%)$ \\
\hline 604.9 & 0.0455 & $\mathrm{H} \rightarrow \mathrm{L}+1(79 \%), \mathrm{H}-2 \rightarrow \mathrm{L}+1(7 \%), \mathrm{H} \rightarrow \mathrm{L}(4 \%), \mathrm{H}-1 \rightarrow \mathrm{L}+1(3 \%), \mathrm{H}-2 \rightarrow \mathrm{L}(2 \%)$ \\
\hline 551.7 & 0.1554 & $\mathrm{H}-1 \rightarrow \mathrm{L}+1(47 \%), \mathrm{H}-2 \rightarrow \mathrm{L}+1(22 \%), \mathrm{H}-1 \rightarrow \mathrm{L}(13 \%), \mathrm{H}-2 \rightarrow \mathrm{L}(12 \%), \mathrm{H} \rightarrow \mathrm{L}(2 \%)$ \\
\hline 550.5 & 0.0548 & $\mathrm{H}-2 \rightarrow \mathrm{L}(73 \%), \mathrm{H}-2 \rightarrow \mathrm{L}+1(15 \%), \mathrm{H}-1 \rightarrow \mathrm{L}(4 \%), \mathrm{H} \rightarrow \mathrm{L}(2 \%)$ \\
\hline 520.2 & 0.0708 & $\mathrm{H}-2 \rightarrow \mathrm{L}+1(47 \%), \mathrm{H}-1 \rightarrow \mathrm{L}+1(17 \%), \mathrm{H} \rightarrow \mathrm{L}+1(13 \%), \mathrm{H}-1 \rightarrow \mathrm{L}(11 \%), \mathrm{H} \rightarrow \mathrm{L}+2(4 \%)$ \\
\hline
\end{tabular}
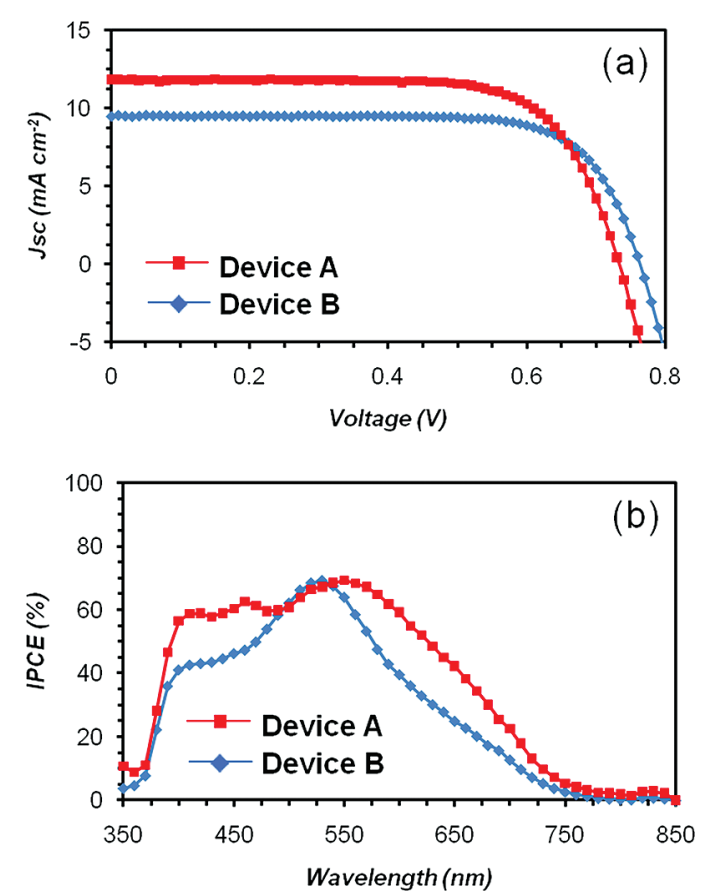

Figure 4. (a) Photocurrent density-voltage characteristic curves under full sunlight (AM 1.5G, $100 \mathrm{~mW} \mathrm{~cm}^{-2}$ ) of devices A and B sensitized with CYC-B12 or Z907Na in combination with the low-volatile electrolyte, Z946. (b) The corresponding incident photon-to-current action spectra of devices sensitized with CYC-B12 or Z907Na. (Thickness of $\mathrm{TiO}_{2}$ film thickness is $3 \mu \mathrm{m}$; cell active area tested with a mask: $0.158 \mathrm{~cm}^{2}$.)

that the energy levels of the ground and excited states for CYCB12 match well the energetic requirements of a dye for efficient charge generation in DSSCs. ${ }^{2}$

In DSSC devices, thicker $\mathrm{TiO}_{2}$ films have higher surface area and thus enhancing the light-harvesting efficiency of dyesensitized $\mathrm{TiO}_{2}$ films, increasing the short-circuit photocurrent density $\left(J_{\mathrm{sc}}\right)$. However, the open-circuit photovoltage $\left(V_{\mathrm{oc}}\right)$ decreases with increasing the film thickness, due to higher surface area increases also the undesired dark current (due to an increase of surface trap states). Hence, initially the $3 \mu \mathrm{m}$ thin $\mathrm{TiO}_{2}$ films were used to fabricate DSSCs, taking the advantage of the high
Table 2. Detailed Photovoltaic Parameters of CYC-B12 and Z907Na-Sensitized Devices under AM 1.5G Simulated Sunlight $\left(100 \mathrm{~mW} / \mathrm{cm}^{2}\right)$ Illumination

\begin{tabular}{lcccccc}
\multicolumn{7}{c}{$\mathrm{TiO}_{2}$ thickness } \\
\multicolumn{1}{c}{ dye } & $(\mu \mathrm{m})$ & electrolyte & $\begin{array}{c}J_{\mathrm{sc}} \\
\left(\mathrm{mA} / \mathrm{cm}^{2}\right)\end{array}$ & $V_{\text {oc }}(\mathrm{V})$ & FF & $\eta(\%)$ \\
\hline CYC-B12 & 3 & $\mathrm{Z} 946$ & 11.8 & 0.733 & 0.71 & 6.2 \\
Z907Na & 3 & $\mathrm{Z} 946$ & 9.5 & 0.763 & 0.74 & 5.3 \\
CYC-B12 & $7+5$ & $\mathrm{Z} 946$ & 16.3 & 0.705 & 0.70 & 8.2 \\
Z907Na & $7+5$ & $\mathrm{Z} 946$ & 14.8 & 0.763 & 0.70 & 7.9 \\
CYC-B12 & $7+5$ & $\mathrm{Z} 960$ & 17.9 & 0.703 & 0.74 & 9.4 \\
\hline
\end{tabular}

optical cross section of CYC-B12 compared to Z907Na ${ }^{36}$ sensitizer. These cells employed an electrolyte (Z946), containing 1.0 M 1,3-dimethylimidazolium iodide (DMII), $0.15 \mathrm{M} \mathrm{I}_{2}$, $0.5 \mathrm{M}$ N-butyl benzimidazole (NBB) and $0.1 \mathrm{M}$ guanidinium thiocyanate (GNCS) as solutes, 3-methoxypropionitrile as the solvent. The characteristic $J-V$ curves of the devices sensitized with CYC-B12 or Z907Na are displayed in Figure 4a. Encouragingly, even with such thin titania film and low-volatile electrolyte, device (device A) based on CYC-B12 in the presence of DINHOP $^{30}$ as a coadsorbent (4:1 molar ratio in the dye solution) provides a $J_{\text {sc }}$ of $11.8 \mathrm{~mA} / \mathrm{cm}^{2}$, a $V_{\text {oc }}$ of $0.733 \mathrm{~V}$ and a FF (fill factor) of 0.71 , yielding an overall power conversion efficiency (PCE) of $6.2 \%$ under illumination with standard AM $1.5 \mathrm{G}$ simulated sunlight $\left(100 \mathrm{~mW} / \mathrm{cm}^{2}\right)$. Under the same conditions, the PCE of $\mathbf{Z 9 0 7 N a}$ sensitized cell (device B) is only $5.3 \%$. The detailed photovoltaic parameters of devices are summarized in Table 2. The major difference in the photovoltaic performance between these two cells is the $J_{s c}$, which was further verified from the corresponding incident-photon to current conversion efficiency (IPCE) spectra illustrated in Figure $4 \mathrm{~b}$. The results reveal the potential of CYC-B12 to be employed in the all-solid-state, plastic and transparent dye sensitized solar cells where thinner $\mathrm{TiO}_{2}$ films are required.

A device (device C) based on CYC-B12 employed a doublelayered $\mathrm{TiO}_{2}$ film $(7+5) \mu \mathrm{m}$ and the low-volatile electrolyte, Z946, was also fabricated and its $J-V$ characteristic curve is displayed in Figure 5a. The photovoltaic parameters are $J_{\mathrm{sc}}=16.3$ $\mathrm{mA} / \mathrm{cm}^{2}, V_{\mathrm{oc}}=0.705 \mathrm{~V}$ and $\mathrm{FF}=0.70$, as summarized in Table 2, yielding the PCE of $8.2 \%$. The corresponding IPCE spectrum is 

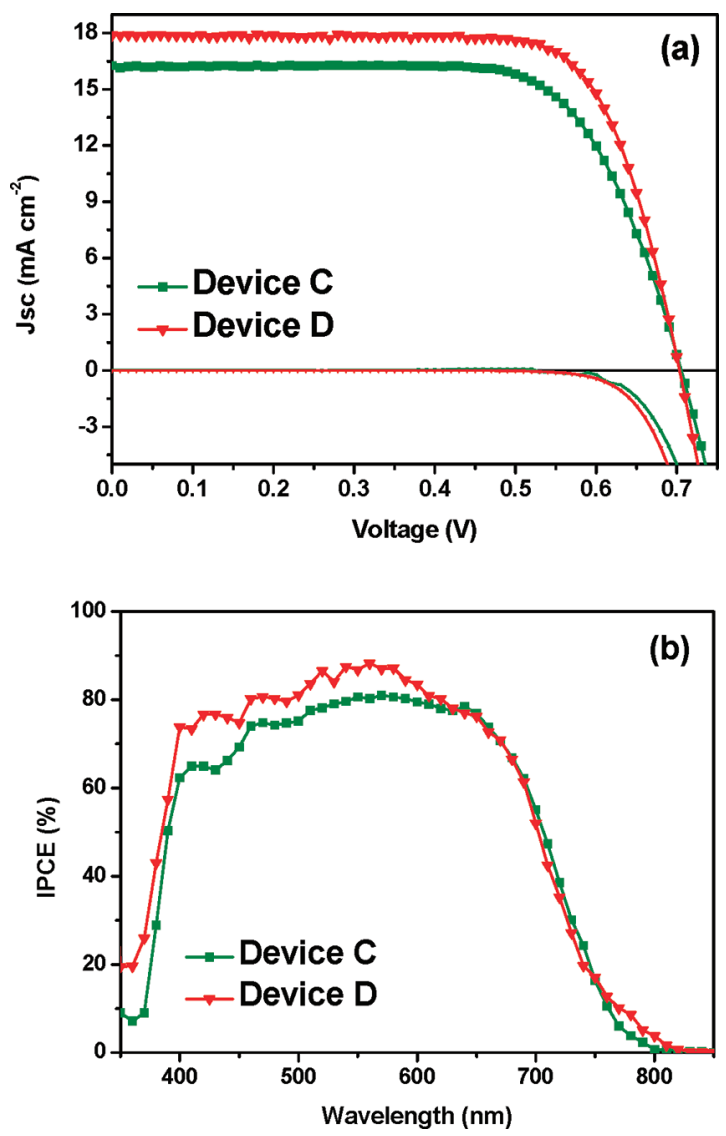

Figure 5. (a) Photocurrent density-voltage characteristic curves of device C and D sensitized with CYC-B12 conjunction with Z946 and Z960, respectively and measured under AM 1.5G simulated sunlight illumination $\left(100 \mathrm{~mW} / \mathrm{cm}^{2}\right)$ and in dark. (b) The corresponding incident photon-to-current action spectra of devices. (Thickness of $\mathrm{TiO}_{2}$ film: $(7+5 \mu \mathrm{m})$; cell active area tested with a mask: $0.158 \mathrm{~cm}^{2}$.)

shown in Figure 5 b which exhibits a plateau of over $70 \%$ from 450 to $670 \mathrm{~nm}$, with the maximum of $81 \%$ at $570 \mathrm{~nm}$. On the other hand the efficiency for Z907Na sensitized device fabricated with the same procedures is $7.9 \% .^{33}$ The detailed photovoltaic parameters are listed in Table 2. Apparently the efficiency of CYCB12 containing devices is higher than the devices with $\mathrm{Z907Na}$ dye. The higher $J_{\text {sc }}$ for CYC-B12 based device (compared to that sensitized with $\mathrm{Z907Na)}$ is mainly due to the higher light absorption capacity of CYC-B12. As expected, the $J_{\text {sc }}$ for thick film device (device $\mathrm{C}$ ) is also higher than that for the thin film device (device A). However, CYC-B12 yields a $58 \mathrm{mV}$ lower $V_{\text {oc }}$ than $\mathrm{Z} 907 \mathrm{Na}$ indicating a faster interfacial electron recapture by triiodide with the former compared to the latter device. This might be caused by the lower CYC-B12 loading and therefore more naked $\mathrm{TiO}_{2}$ surface might be exposed to the electrolyte. To prove this supposition, the dye loading of both CYC-B12 and Z907Na on $8 \mu \mathrm{m}$ thick transparent $\mathrm{TiO}_{2}$ film was measured. It was found that the amount of CYC-B12 dye $\left(2.31 \times 10^{-8} \mathrm{~mol}\right)$ on the surface of $\mathrm{TiO}_{2}$ is almost two times lower than that of Z907Na dye $\left(4.18 \times 10^{-8} \mathrm{~mol}\right)$, which accounts for the lower $V_{\text {oc }}$ value of device sensitized by CYC-B12.

The composition of the electrolyte exerts a strong effect on the performance of CYC-B12 sensitized devices. The $J-V$ curve for device D used a standard volatile electrolyte coded Z960 (the composition of Z960 electrolyte can be found in the
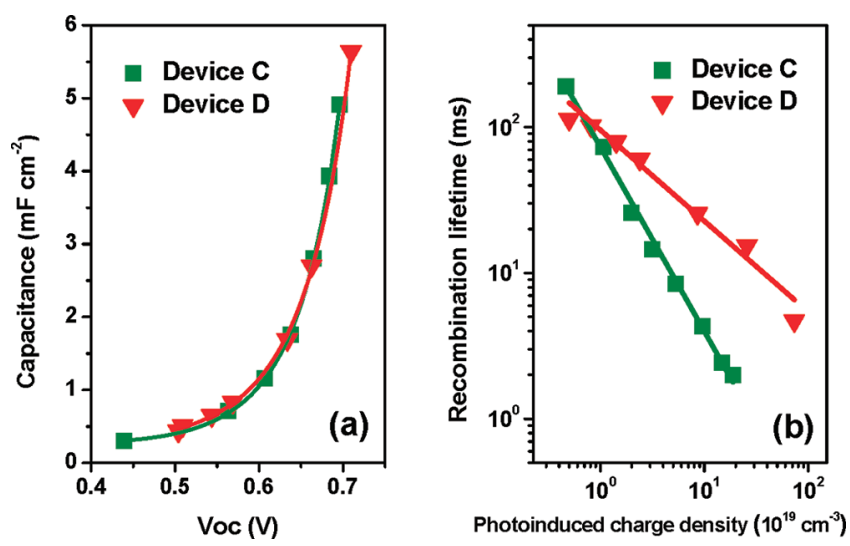

Figure 6. Transient photoelectrical measurements of device $\mathrm{C}$ and $\mathrm{D}$ based on CYC-B12 in conjunction with Z946 and Z960 electrolyte, respectively. (a) Chemical capacitance of devices as a function of $V_{\text {oc. }}$ (b) Recombination lifetime of devices as a function of photoinduced charge density.

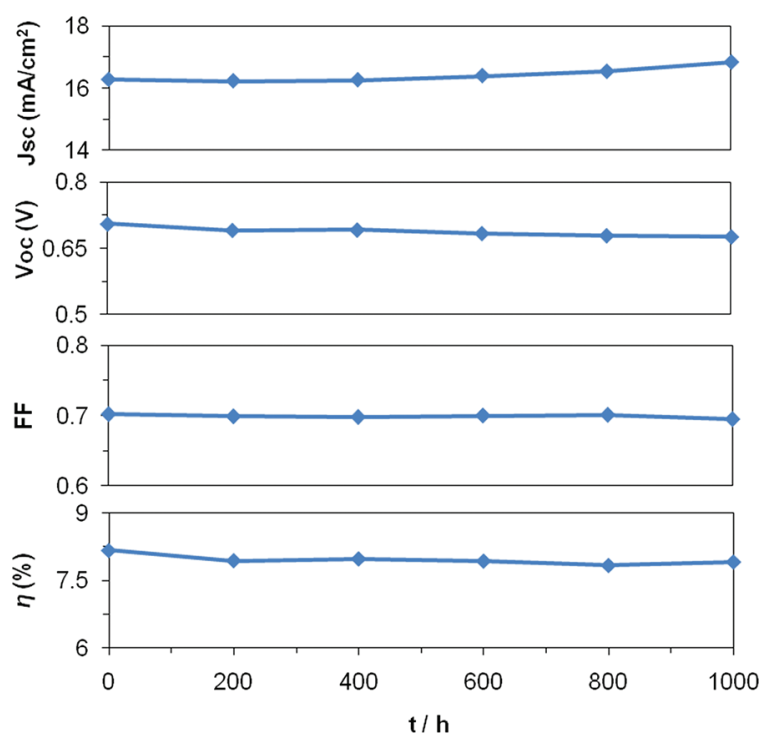

Figure 7. Evolution of the photovoltaic parameters $\left(J_{\mathrm{sc}}, V_{\mathrm{oc}}, \mathrm{FF}\right.$, and $\left.\eta\right)$ for the device C sensitized with CYC-B12 in combination with a lowvolatile liquid electrolyte (Z946) during the visible light-soaking (1 sun; $\left.100 \mathrm{~mW} / \mathrm{cm}^{2}\right)$ at $60{ }^{\circ} \mathrm{C}$.

Experimental Section) is also displayed in Figure 5a. Device D provides a $J_{\mathrm{sc}}$ of $17.9 \mathrm{~mA} / \mathrm{cm}^{2}$, a $V_{\mathrm{oc}}$ of $0.703 \mathrm{~V}$ and a FF of 0.74 , yielding a high conversion efficiency of $9.4 \%$. The corresponding IPCE spectrum presented in Figure $5 \mathrm{~b}$ shows a plateau of over $80 \%$ from 460 to $620 \mathrm{~nm}$ with the maximum of $88 \%$ at $560 \mathrm{~nm}$. The difference in $J_{\mathrm{sc}}$ for device $\mathrm{C}$ and $\mathrm{D}$ can be rationalized in terms of the physical diffusion of iodide/triiodide in the electrolyte. 6,37 In general, a faster transportation of iodide/ triiodide can be achieved in a higher volatile electrolyte. Z960 electrolyte (for device D) has lower viscosity and lower concentration of triiodide compared to Z946 electrolyte (for device C). Electrolyte with low viscosity and triiodide concentration benefits the dye regeneration and the charge carrier collection efficiency. ${ }^{37,38}$ It is also known that the $V_{\text {oc }}$ of a DSSC is determined intrinsically by the potential difference between the 

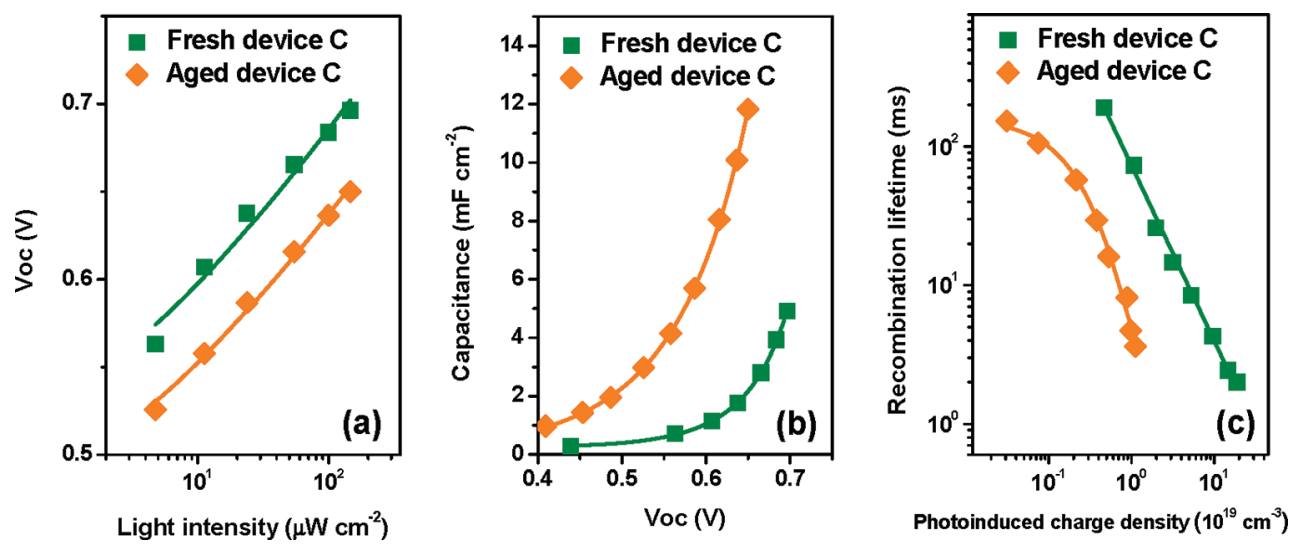

Figure 8. Transient photoelectrical measurements of the fresh and aged device C sensitized with CYC-B12 in conjunction with Z946 electrolyte. (a) Open-circuit voltage for devices as a function of incident light intensity. (b) Chemical capacitance of devices as a function of $V_{\text {oc }}$. (c) Recombination lifetime of devices as a function of photoinduced charge density.

quasi-Fermi level of the semiconductor $\left(\mathrm{TiO}_{2}\right)$ and the redox potential of the hole-conductor (or electrolyte). Nevertheless, the $V_{\text {oc }}$ will be affected by a shift of $\mathrm{TiO}_{2}$ conduction band edge ${ }^{39}$ as well as the degree of electron recombination. ${ }^{40,41}$ To scrutinize the difference in the electron recombination dynamics between injected electrons in CYC-B12 sensitized $\mathrm{TiO}_{2}$ and triiodide, the transient photoelectrical measurements ${ }^{42,43}$ were performed. The chemical capacitance of device $\mathrm{C}$ and $\mathrm{D}$ as a function of $V_{\text {oc }}$ showed in Figure 6a reveals in the same distribution of the surface trap states when different liquid electrolytes are used. In spite of this, the recombination lifetime of device $\mathrm{D}$ is remarkably longer than that of device $\mathrm{C}$ at high photoinduced charge density although at low charge density the difference is small (see Figure $6 \mathrm{~b}$ ). These results reveal that the well-modulated LiI and tert-butylpyridine concentration in Z960 electrolyte can effectively facilitate the electron injection and retard the charge recombination ${ }^{44-46}$ and are responsible for the higher efficiency of device D. Furthermore, we can compare the photovoltaic performances of device $\mathrm{C}$ and device $\mathrm{D}$ with the corresponding devices sensitized by CYC-B13. ${ }^{25}$ The higher $J_{\mathrm{sc}}$ achieved by CYC-B12 based device is attributed to the increase in the lightharvesting ability.

In addition to the photon-to-current conversion efficiency, the stability of photovoltaic device is also a critical factor for the practical application. To demonstrate the durability of the device sensitized by CYC-B12, device C was subjected to the accelerated aging test performed under the illumination with the visible light $\left(1 \mathrm{sun} ; 100 \mathrm{~mW} / \mathrm{cm}^{2}\right)$ at $60{ }^{\circ} \mathrm{C}$. As displayed in Figure 7, the photovoltaic parameters $J_{\mathrm{sc}}, V_{\mathrm{oc}}, \mathrm{FF}$, and $\eta$ of the device $\mathrm{C}$ slightly changed to $16.8 \mathrm{~mA} / \mathrm{cm}^{2}, 0.676 \mathrm{~V}, 0.70$, and $7.9 \%$, respectively and the $\eta$ retained $96 \%$ of its initial value after $1000 \mathrm{~h}$ of light soaking and thermal stressing. The preliminary results reveal that CYC-B12 can sustain excellent stability under prolonged light soaking at elevated temperatures. The thienothiophene-linked carbazole antennas on CYC-B12 not only can effectively prevent the desorption of the self-assembled dye molecules, induced by water during the accelerated aging process, but also can maintain the light-harvesting ability of the corresponding DSSC device. Furthermore, by comparing the stability of the devices sensitized by CYC-B13 ${ }^{25}$ and CYC-B12, it seems that having EDOT or thieno[3,2-b] thiophene as $\pi$-bridge in the ancillary ligand show little influence on the device stability. To diagnose the changes of the photovoltaic parameters for the device during the long-term light-soaking and thermal stressing test, the transient photovoltage measurements were performed on the device $\mathrm{C}$ before and after aging. Figure 8a displays the open-circuit voltage as a function of the incident light intensity. Under the same light intensity, the $V_{\text {oc }}$ decreases upon aging, indicating that after light soaking, the conduction band edge of $\mathrm{TiO}_{2}$ may undergo a downward shift (to more positive potentials), resulting in slightly decreasing the open circuit voltage. This scenario has been observed previously in DSSCs, was attributed to the photoinduced proton intercalation of the titania. ${ }^{47}$ To clarify the $V_{\text {oc }}$ degrading mechanism upon aging, the transient photoelectrical studies were performance and the results are displayed in Figure 8. The chemical capacitance for both fresh and aged device $\mathrm{C}$ increases exponentially with increasing light intensity. At the identical $V_{\text {oc }}$, the capacitance of the aged device $C$ is higher than that for the fresh one (Figure $8 \mathrm{~b}$ ), revealing a larger density of surface trap states below the conduction band edge caused by $1000 \mathrm{~h}$ light soaking. Furthermore, at the same photoinduced charge density $\left(1 \times 10^{19} \mathrm{~cm}^{-3}\right.$, for example) the recombination lifetime $(3.6 \mathrm{~ms})$ for the aged device $\mathrm{C}$ is significantly shorter than that $(73.0 \mathrm{~ms})$ for the fresh device $\mathrm{C}$ as shown in Figure 8c. In spite of this, the overall conversion efficiency for the aged device $\mathrm{C}$ is close to that of the fresh device $\mathrm{C}$ because the increase in charge recombination rate can be compensated by increasing the short-circuit current upon aging.

\section{CONCLUSION}

In summary, we report a new high light-harvesting ruthenium sensitizer, CYC-B12, endowed with a new antenna consisting of the sequential connection of a thienothiophene conjugated bridge and carbazole hole-transport moiety. DSSC based on this new sensitizer with a volatile liquid electrolyte exhibits a 9.4\% conversion efficiency under AM 1.5G sunlight. Excellent cell stability under prolonged light soaking and thermal stressing is also demonstrated with a low-volatility liquid electrolyte. The physicochemical data clearly show that CYC-B12 is a good dye for efficient and robust DSSCs. Moreover, the transient photoelectrical data for the devices with different electrolytes indicate that the variation in the electron recombination lifetime, due to the change in the triiodide concentration, is the main reason for the divergence of the cell performance. 


\section{AUTHOR INFORMATION}

\section{Corresponding Author}

*E-mail: shaik.zakeer@epfl.ch; t610002@cc.ncu.edu.tw; michael. graetzel@epfl.ch.

\section{ACKNOWLEDGMENT}

Financial support from the National Science Council, Taiwan, ROC, and the Swiss National Science Foundation, and the computer time and facilities from the National Center for High-performance Computing and the Vger computer cluster at the National Central University, Taiwan, ROC are all gratefully acknowledged. We thank Dr. Robin Humphry-Baker for fruitful discussions.

\section{REFERENCES}

(1) O’Regan, B.; Grätzel, M. Nature 1991, 353, 737.

(2) Grätzel, M. Acc. Chem. Res. 2009, 42, 1788.

(3) Hagfeldt, A.; Boschloo, G.; Sun, L.; Kloo, L.; Pettersson, H. Chem. Rev. 2010, 110, 6595.

(4) Mishra, A.; Fischer, M. K. R.; Bäuerle, P. Angew. Chem., Int. Ed. 2009, 48, 2474.

(5) Ooyama, Y.; Harima, Y. Eur. J. Org. Chem. 2009, 2903.

(6) Zakeeruddin, S. M.; Grätzel, M. Adv. Funct. Mater. 2009, $19,2187$.

(7) Chen, C. Y.; Wu, S. J.; Wu, C. G.; Chen, J. G.; Ho, K. C. Angew. Chem. 2006, 118, 5954. Angew. Chem., Int. Ed. 2006, 45, 5822.

(8) Chen, C. Y.; Lu, H. C.; Wu, C. G.; Chen, J. G.; Ho, K. C. Adv. Funct. Mater. 2007, 17, 29.

(9) Chen, C. Y.; Wu, S. J.; Wu, C. G.; Chen, J. G.; Ho, K. C. Adv. Mater. 2007, 19, 3888.

(10) Gao, F.; Wang, Y.; Zhang, J.; Shi, D.; Wang, M.; HumphryBaker, R.; Wang, P.; Zakeeruddin, S. M.; Grätzel, M. Chem. Commun. 2008, 2635.

(11) Gao, F.; Wang, Y.; Shi, D.; Zhang, J.; Wang, M.; Jing, X.; Humphry-Baker, R.; Wang, P.; Zakeeruddin, S. M.; Grätzel, M. J. Am. Chem. Soc. 2008, 130, 10720.

(12) Shi, D.; Pootrakulchote, N.; Li, R.; Guo, J.; Wang, Y.; Zakeeruddin, S. M.; Grätzel, M.; Wang, P. J. Phys. Chem. C 2008, 112, 17046.

(13) Abbotto, A.; Barolo, C.; Bellotto, L.; De Angelis, F.; Grätzel, M.; Manfredi, N.; Marinzi, C.; Fantacci, S.; Yum, J. H.; Nazeeruddin, M. K. Chem. Commun. 2008, 5318.

(14) Cao, Y.; Bai, Y.; Yu, Q.; Cheng, Y.; Liu, S.; Shi, D.; Gao, F.; Wang, P. J. Phys. Chem. C 2009, 113, 6290.

(15) Yu, Q.; Liu, S.; Zhang, M.; Cai, N.; Wang, Y.; Wang, P. J. Phys. Chem. C 2009, 113, 14559.

(16) Willinger, K.; Fischer, K.; Kisselev, R.; Thelakkat, M. J. Mater. Chem. 2009, 19, 5364.

(17) Sauvage, F.; Fischer, M. K. R.; Mishra, A.; Zakeeruddin, S. M.; Nazeeruddin, M. K.; Bäuerle, P.; Grätzel, M. ChemSusChem 2009, 2,761 .

(18) Chen, C. Y.; Wang, M.; Li, J. Y.; Pootrakulchote, N.; Alibabaei, L.; Ngoc-le, C.; Decoppet, J. D.; Tsai, J. H.; Grätzel, C.; Wu, C. G.; Zakeeruddin, S. M.; Grätzel, M. ACS Nano 2009, 3, 3103.

(19) Mishra, A.; Pootrakulchote, N.; Fischer, M. K. R.; Klein, C.; Nazeeruddin, M. K.; Zakeeruddin, S. M.; Bäuerle, P.; Grätzel, M. Chem. Commun. 2009, 7146.

(20) Wu, K. L.; Hsu, H. C.; Chen, K.; Chi, Y.; Chung, M. W.; Liu, W. H.; Chou, P. T. Chem. Commun. 2010, 5124.

(21) Mishra, A.; Pootrakulchote, N.; Wang, M.; Moon, S. J.; Zakeeruddin, S. M.; Grätzel, M.; Bäuerle, P. Adv. Funct. Mater. 2011, 21, 963.

(22) Haque, S. A.; Handa, S.; Peter, K.; Palomares, E.; Thelakkat, M.; Durrant, J. R. Angew. Chem. 2005, 117, 5886. Angew. Chem., Int. Ed. 2005, 44, 5740 .
(23) Chen, C. Y.; Chen, J. G.; Wu, S. J.; Li, J. Y.; Wu, C. G.; Ho, K. C. Angew. Chem. 2008, 120, 7452. Angew. Chem., Int. Ed. 2008, 47, 7342.

(24) Choi, H.; Baik, C.; Kim, S.; Kang, M. S.; Xu, X.; Kang, H. S.; Kang, S. O.; Ko, J.; Nazeeruddin, M. K.; Grätzel, M. New J. Chem. 2008, 32, 2233.

(25) Chen, C. Y.; Pootrakulchote, N.; Wu, S. J.; Wang, M.; Li, J. Y.; Tsai, J. H.; Wu, C. G.; Zakeeruddin, S. M.; Grätzel, M. J. Phys. Chem. C 2009, 113, 20752.

(26) Li, J. Y.; Chen, C. Y.; Chen, J. G.; Tan, C. J.; Lee, K. M.; Wu, S. J.; Tung, Y. L.; Tsai, H. H.; Ho, K. C.; Wu, C. G. J. Mater. Chem. 2010, 20, 7158 .

(27) Leriche, P.; Raimundo, J. M.; Turbiez, M.; Monroche, V.; Allain, M.; Sauvage, F. X.; Roncali, J.; Frère, P.; Skabara, P. J. J. Mater. Chem. 2003, 13, 1324.

(28) Hameurlaine, A.; Dehaen, W. Tetrahedron Lett. 2003, 44, 957.

(29) Wang, P.; Zakeeruddin, S. M.; Comte, P.; Charvet, R.; Humphry-Baker, R.; Grätzel, M. J. Phys. Chem. B 2003, 107, 14336.

(30) Wang, M.; Li, X.; Lin, H.; Pechy, P.; Zakeeruddin, S. M.; Grätzel, M. Dalton Trans. 2009, 10015.

(31) Frisch, M. J. et al. Gaussian 09, revision A.02; Gaussian, Inc.: Wallingford, CT, 2009.

(32) Godbout, N.; Salahub, D. R.; Andzelm, J.; Wimmer, E. Can. J. Chem. 1992, 70, 560 .

(33) Barolo, C.; Nazeeruddin, M. K.; Fantacci, S.; Di Censo, D.; Comte, P.; Liska, P.; Viscardi, G.; Quagliotto, P.; De Angelis, F.; Ito, S.; Grätzel, M. Inorg. Chem. 2006, 45, 4642.

(34) Barone, V.; Cossi, M. J. Phys. Chem. A 1998, 102, 995.

(35) Cossi, M.; Rega, N.; Scalmani, G.; Barone, V. J. Comput. Chem. 2003, 24, 669.

(36) Wang, P.; Klein, C.; Humphry-Baker, R.; Zakeeruddin, S. M.; Grätzel, M. J. Am. Chem. Soc. 2005, 127, 808.

(37) Zhang, Z.; Ito, S.; Moser, J. E.; Zakeeruddin., S. M.; Grätzel, M. ChemPhysChem 2009, 10, 1834.

(38) Boschloo, G.; Hagfeldt, A. Acc. Chem. Res. 2009, 42, 1819.

(39) Zhang, Z.; Zakeeruddin, S. M.; O’Regan, B.; Humphry-Baker, R.; Grätzel, M. J. Phys. Chem. B 2005, 109, 21818.

(40) Reynal, A.; Forneli, A.; Martinez-Ferrero, E.; Sánchez-Díaz, A.; Vidal-Ferran, A.; O’Regan, B.; Palomares, E. J. Am. Chem. Soc. 2008, 130, 13558.

(41) O'Regan, B.; Walley, K.; Juozapavicius, M.; Anderson, A.; Matar, F.; Ghaddar, T.; Zakeeruddin, S. M.; Klein, C.; Durrant, J. R. J. Am. Chem. Soc. 2009, 131, 3541.

(42) O’Regan, B.; Lenzmann, F. J. Phys. Chem. B 2004, 108, 4342.

(43) Bailes, M.; Cameron, P. J.; Lobato, K.; Peter, L. M. J. Phys. Chem. B 2005, 109, 15429.

(44) Haque, S. A.; Palomares, E.; Cho, B. M.; Green, A. N. M.; Hirata, N.; Klug, D. R.; Durrant, J. R. J. Am. Chem. Soc. 2005, 127, 3456.

(45) Katoh, R.; Kasuya, M.; Kodate, S.; Furube, A.; Fuke, N.; Koide, N. J. Phys. Chem. C 2009, 113, 20738.

(46) Koops, S. E.; O’Regan, B.; Barnes, P. R.; Durrant, J. R. J. Am. Chem. Soc. 2009, 131, 4808.

(47) Wang, Q.; Zhang, Z.; Zakeeruddin, S. M.; Grätzel, M. J. Phys. Chem. C 2008, 112, 7084. 